\title{
Effects of Dynamic Assessment on the Acquisition of the Rhythm of English: The Case of EFL Learners' Attitudes
}

\author{
Sajad Shafiee ${ }^{1}$, Fahimeh Talakoob ${ }^{2} \&$ Mina Fatahi $^{2}$ \\ ${ }^{1}$ Department of English, Shahrekord Branch, Islamic Azad University, Shahrekord, Iran \\ ${ }^{2}$ Department of English, Isfahan (Khorasgan) Branch, Islamic Azad University, Isfahan, Iran \\ Correspondence: Sajad Shafiee, Department of English, IAU, Shahrekord Branch, Shahrekord, Iran. E-mail: \\ s.shafiee@iaushk.ac.ir
}

Received: April 15, 2018 Accepted: May 7, 2018 Online Published: June 9, 2018

doi:10.5539/ijel.v8n5p181 URL: https://doi.org/10.5539/ijel.v8n5p181

\begin{abstract}
Dynamic assessment has been widely used in educational literature over the past two decades. The present study aimed at investigating the effect of using dynamic assessment on teaching the rhythm of English to Iranian EFL learners and scrutinizing their attitudes towards it. The participants of the study were 30 Iranian EFL leaners at the intermediate level of proficiency, who were conveniently selected from a foreign language institute in Isfahan, Iran. In order to achieve the objectives of the study, the participants were divided into two homogenous groups, including the experimental group and control group. In this quasi-experimental, pretest-posttest-control-group-design research study, the control group followed traditional method of learning pronunciation and rhythm, while dynamic assessment approach was used to teach the same materials to the experimental group. In contrast to the control group, the experimental group took an active role in the classroom by having more interaction and using the ongoing hints and prompts provided by the teacher. The result of the posttest unfolded that there was a significant difference between the performances of the two groups, and that the experimental group participants managed to outperform the control group members on the pronunciation posttest. Moreover, based on the attitude questionnaire, EFL learners had grown a positive attitude towards the use of dynamic assessment to learn rhythm. The results of this study demonstrated that through the implementation of DA, the proper form of mediation could be provided to the learners regarding their ZPD.
\end{abstract}

Keywords: dynamic assessment, formative assessment, summative assessment, pronunciation, rhythm, attitude

\section{Introduction}

One of the important aspects of learning a foreign language is developing adequate pronunciation skills. This is while a lot of graduates from the foreign language programs offered all around the world seem to be unable to develop enough competence in the skills and sub-skills of the target language they study, especially in pronunciation (Vellenga, 2004). While they have had extensive instruction and practice in pronunciation, they still fail to learn to accurately articulate the words in sentences they produce. One of the consequences of this phenomenon is inability to communicate well.

Pronunciation is very much a challenge for any English language learner for different reasons. Among so many reasons for the EFL learners' lack of enough pronunciation skills, especially rhythm, there are three very important ones. Firstly, it is difficult for teachers to spend enough time on pronunciation with students. Secondly, there are so many students in a class, each with different needs. The third reason is that there are not fully-fledged specified approaches which offer techniques to teach pronunciation. Among the three reasons mentioned above, the third one seems to be of greater significance because this sub-skill is usually ignored in language classes due to this reason. The reason for this inattention is that it is often found boring to teach by teachers as Foote, Quinney, and Taylor (2013) found it to be true in their study. Therefore, research on new approaches to instruction and assessment is necessary. Among these approaches addressed recently by researchers, Dynamic Assessment (DA), originating from Vygotsky's (1978) social constructivist theories, has been attracting considerably more and more attention. In contexts of EFL, dynamic assessment is not a very recent phenomenon. Dealing with the Zone of Proximal Development (ZPD) of learners, it is a relative term to be defined (Hanifi, Nasiri, \& Aliasin, 2016). In fact, various definitions have been given by different researchers for DA in the literature. For example, Leung (2007) defines it as a new approach to assessment which is based 
on dynamic interaction between the person who examines and the examinee. According to Hanifi et al. (2016), in this process, the examiner provides leading questions and prompts so as to mediate the learning in the examinees.

In teaching English as a second or foreign language, while learning English involves competence in different aspects such as grammar and vocabulary, pronunciation is also one of the most important skills which needs close attention. Since sounds play an important role in communication, foreign language teachers must attach special importance to teaching pronunciation in their classes. In spite of the significance of pronunciation in learning a new language, making it an integral part of instruction, teaching of ESL/EFL pronunciation is currently not optimally effective to a desired point. While it must have originated from different resources, in one way, this problem can be attributed to inefficient approaches to teaching pronunciation.

\section{Literature Review}

One of the key requirements for language proficiency is to secure understandable pronunciation for the language learners. According to Morley (1991), it is necessary that both teachers and learners change roles and teaching methodologies change objectives. Teachers must act as pronunciation coaches and learners must be proactive learners taking the initiative to learn.

Pronunciation is an essential component not only of learning a language, but also of using that language. For this reason, learning proper pronunciation is a delicate area; students need to feel free to make mistakes and practice their pronunciation in order to increase their accuracy, but there are also times when pronunciation must be quickly corrected so that it does not impede the students' ability to understand and be understood.

Rhythm, in fact, is timing patterns amid syllables. The timing patterns are not similar in all languages. Rhythmic structure is a fundamental feature of both speech and music. According to Valle (2016), our spoken language is inevitably linked to music. This can be seen in the suprasegmental features of the speech because prosody is defined as changes in voice and rhythm of speech. Therefore, it is possible to establish a clear analogy between speech and musicality. There are, principally, two contrary sorts of rhythm in languages: stress-timed and syllable-timed. According to Mackay (1985), stress-timed rhythm is decided by stressed syllables that happen at standard gaps of time, with an irregular and varying number of unstressed syllables among them; syllable-timed rhythm is founded on the whole number of syllables as each syllable receives roughly identical quantity of time. Young listeners must also disentangle musical from linguistic input despite many overlapping elements and features. Because rhythm is prominent in music and language but variable across cultures, it is a potentially important source of information about culture-specific content and structure (Hannon, Lévêque, Nave, \& Trehub, 2016).

In EFL contexts, dynamic assessment is not a very recent phenomenon. Dealing with the Zone of Proximal Development (ZPD) of learners, it is a relative term to be defined (Hanifi et al., 2016). Various definitions have been given by different researchers for DA in the literature. For example, Leung (2007) defines it as a new approach to assessment which is based on dynamic interaction between the person who examines and the examinee. According to Hanifi et al. (2016), in this process, the examiner provides leading questions and prompts so as to mediate the examinee.

As mentioned above, dynamic assessment, which is a subdivision of formative assessment, finds its origin in Vygotsky's socio-cultural principles. It is in effect an alternative to static assessment. It makes it possible to understand individual differences and their implications for instruction that embed intervention within the assessment procedure (Lidz \& Gindis, 2003). It has resulted in a significant improvement regarding different aspects of language learning over the traditional assessment or non-dynamic assessment, which only reveals the abilities that have been already developed (Ajideh \& Nourdad, 2012). The dynamic score and the analysis of the ZPD make it possible to find out about the abilities that have not developed yet, but can be developed in collaboration with a more knowledgeable person (Ajideh, Farrokhi, \& Nourdad, 2012).

The above-mentioned introduction on the subject of DA provides evidence of the utility of this approach for many learning/teaching situations. As a modern approach to assessment, DA can be used to evaluate the progress EFL learners make in each skill or sub-skill. In dynamic assessment the goal of assessment is very different. As a matter of fact, current level of performance is not the focus of interest. The assessor's objective is rather to understand, from the way in which a child learns, to improve their performance in the course of given cognitive tasks (Deutsch \& Raynolds, 2000). In order to achieve this detailed understanding, the assessor must interact with the child during the performance of the tasks. Therefore, DA can be investigated to see whether it can offer a unanimous, organized approach to teaching pronunciation sub-skills, for instance rhythm. 
Dynamic assessment (DA) has become a significant trend for researchers and theorists over the past years. It is seen as an approach which understands individual differences and their implications for instruction and embeds intervention within the assessment procedure by including appropriate forms of mediation that are sensitive to the individual's current abilities and subsequent performance with the aim of promoting learner development (Lidz \& Gindis, 2003). In other words, DA differs from traditional assessment in terms of the theoretical orientation, the assessment procedures employed, and the interpretation of results (Carney \& Cioffi, 1992). It is about the relationship between assessment and instruction. More specifically, DA focuses on the evaluation process as well as the product. It attempts to modify the student's performance during testing by introducing material or instructions to elicit higher achievement levels (Embretson \& Wetzel, 1987).

There are a number of approaches and models that fall under the umbrella term of DA. This is due to the fact that mediation can be implemented in a number of ways. However, Lantolf and Poehner (2004) identified two general approaches to DA: interventionist and interactionist.

The interventionist type of DA includes intervention from the examiner during the test procedure itself and it is a more formal and standardized approach. During interventionist DA, the examinees are given instruction item by item and if they cannot solve the item correctly, they are given pre-fabricated hints. Poehner (2008) stated that the defining characteristic of interventionist DA is the use of standardized administration procedures and forms of assistance to present easily quantifiable results that can be exploited to make comparisons between and within groups, and can be contrasted with other measures and employed to make predictions about performance on future tests.

In a case study, Lin (2010) conducted an interactive DA study in an EFL context. He concludes that administering a set of pre-formulated supportive hints during a test would provide teachers with information about students' needs and their potential responses to meditation. The author then claims that a successful interactive DA program should meet three factors: a) It should have clear objectives, b) It should include meaningful tasks that are in the learner's ZPD and that accommodate to pre-formulated hints and meditations, and c) It should enjoy an appropriate rating scale and appropriate analytic approach.

Ahmadi-Safa, Moradi, and Hamzavi (2015) set to investigate the effects of this assessment procedure on the Iranian advanced EFL learners speaking skill proficiency. Using three groups, two DA groups and one Non-DA group they assigned speaking tasks. The DA group participants were assessed and given the required assistance through interaction based DA procedures, while the second DA group received DA based intervention following Lantolf and Poehner (2011) scale to assess and assist the participants' speaking proficiency in their discussions. They found out that: (a) interactionist model of DA had statistically significant positive effect on Iranian EFL learners' speaking ability; (b) interventionist model of DA had statistically significant positive effect on Iranian EFL learners' speaking ability. Furthermore, with their results they showed that three groups, namely, interactionist DA, interventionist DA, and non- DA had statistically significant different effects on Iranian EFL learners' speaking ability with the interactionist DA group outperforming.

In the same vein, Mardani and Tavakoli (2011) investigated the role of dynamic assessment in reading comprehension of 30 Iranian male learners. During the mediation phase the researchers followed an interactionist method which was based on cooperative dialog. The findings rejected the null hypothesis of the researchers and they concluded that incorporation of DA as a supplementary procedure to standard testing had positive effects on both test performance and learning of learners.

Moreover, Hessamy and Ghaderi (2014) conducted research to investigate the role of dynamic assessment (DA) in the vocabulary learning of EFL learners choosing intermediate level learners and using the pretest-mediation-posttest design (sandwich model of DA). The participants were assigned to two groups. The findings of their study revealed that the learners who received mediation outperformed the others who did not, and this difference was significant. The concluded that incorporation of DA as a supplementary procedure to standard assessment would be conducive to more learning outcomes.

The studies reviewed above show that DA has been welcome by researchers in the realm of SLA; however, research into the potential usefulness of DA for many underexplored areas of SAL, e.g., pronunciation and its components such as rhythm, is yet to be done.

The present study, hence, aimed to investigate the effectiveness of using dynamic assessment to teach the rhythm of English to Iranian EFL learners and to examine their attitudes towards it. Thus, the following research questions were addressed in the present study:

1) Does dynamic assessment have a positive effect on the Iranian EFL learners' pronunciation rhythm? 
2) Do the EFL learners have a positive attitude towards the use of dynamic assessment to learn rhythm of English?

\section{Methodology}

The current research exploited the sandwich format of DA (Sternberg \& Grigorenko, 2002), in which the participants took a traditional static test as a pretest where no mediation was provided. Then, in the second phase, intervention was provided by the teacher for the participants. Subsequently, each participant took a posttest. This design allowed the researchers to compare the participants' performance before and after the mediation intervention. Since there were two groups of conveniently selected participants (i.e., experimental group and control group), pretest and posttest, and the treatment provided for the experimental group learners, the design of the current study was a quasi-experimental pretest-posttest-control-group design. The materials used in the present study included Family and Friends books, a six-level set of course books written to accompany the very successful ELT series. Twenty sentences were selected from the dialogues of the book for both the pretest and the posttest.

\subsection{Participants}

The participants in this study were 30 EFL learners studying English as foreign language in a language institute in Isfahan, Iran, where one of the researchers was employed as a teacher. They were chosen from among 60 learners who were studying English at the intermediate level of language proficiency and were divided into two groups of 15 participants. They were all Iranian speakers of Persian and were aged between 13 and 16. The homogeneity of the two groups in terms of language proficiency had been assured by the institute's placement test and later through the QPT as well as their teachers' judgment.

\subsection{Materials and Instruments}

The instruments which were used in this study included the Quick Placement Test (QPT) to ensure the homogeneity of the groups in terms of their L2 proficiency, a pretest, a posttest, and an attitude questionnaire.

1) Quick Placement Test (QPT): To measure the students' level of English proficiency, the QPT was administered. This was done to select 30 participants at the intermediate level of proficiency. The QPT was chosen because it was objective, reliable as well as easy to administer. The results QPT were also used to divide the participants into two groups. The QPT consists of 60 multiple-choice questions designed to elicit the learners' vocabulary, grammar, and reading comprehension ability. This test has been widely used by the SLA researchers all over the world, and its reliability and validity have been reported by many authors. Those learners who obtained a score between 30 and 47 were regarded as intermediate learners, based on the QPT scoring rubric.

2) Pretest: A pretest on sentence rhythm (a list of 20 sentences to be read aloud by the learners) was chosen to be administered to the students of the two groups at the beginning of experiment. The aim of that was to assure the students' parity in using the English speech rhythm prior to the beginning of the experiment. Two raters, one of the researchers herself and a co-rater who was a colleague in the language institute, rated the learners' rhythm, and the inter-rater reliability of the test scores was measures using Pearson correlation formula $(r=.85)$ and the validity was ascertained through expert judgment.

3) Posttest: A posttest, which was quite similar to the pretest, was also administered to the two groups on the last session of the course. The aim of the posttest was to examine the extent to which the learners' ability to use the English rhythm had improved (if it had at all) in the two groups. Like what was done for the pretest, the inter-rater reliability of test scores was obtained by Pearson correlation formula $(r=.91)$ and the validity of the test was ascertained through expert judgment.

4) Attitude Questionnaire: In order to investigate the experimental group students' attitudes toward the use of dynamic assessment in learning pronunciation, a 15-item researcher-made Likert-scale questionnaire was also developed and administered to the experimental group students at the end of the treatment sessions. The reliability of the questionnaire was analyzed through Cronbach's alpha $(r=.87)$ and its validity was established through expert judgment. The questionnaire was written in the respondents' mother tongue, Persian, in order to ensure their full comprehension of the items and avoid any problems arising from the language barriers.

Content validity of the instrument had to be taken into consideration as well. To assure that the test content corresponded well to the content of instructional materials (i.e., to ensure whether the test included a proper sample of the relevant content words), the test content was analytically matched against the content of the instructional materials by a number of experts in teaching English and testing who were not directly connected with the production of the test in question. Thus, the tests were reviewed by some experts in language teaching and testing to ensure a general consensus among them concerning the content validity of the tests. 
The last instrument, the attitude questionnaire included 15 Likert-scale items, and was subjected to stringent tests of reliability and validity. Therefore, as it was also mentioned above, the reliability of the questionnaire was determined through Cronbach's alpha formula. To determine the validity of the questionnaire, the researchers asked three experts and English teachers to pass their comments on validity and content appropriateness of the questionnaire as well. Content validity of the instrument had to be taken into consideration as well. To assure that the test content corresponded well to the content of instructional materials (i.e., to ensure whether the test included a proper sample of the relevant content words), the test content was analytically matched against the content of the instructional materials by a number of experts in teaching English and testing who were not directly connected with the production of the test in question. Thus, the tests were reviewed by some experts in language teaching and testing to ensure a general consensus among them concerning the content validity of the tests.

\subsection{Procedures}

The present study was designed to investigate the effect of using dynamic assessment to teach rhythm in EFL learners' classroom on the learners' pronunciation skills and their attitudes towards this intervention. To this end, pretest-treatment-posttest design (sandwich model of DA) discussed above was used in the study. To achieve the goals of the study, the learners sat for Quick Placement Test (QPT). This test was run to select 50 students at the intermediate proficiency level. After that, they were randomly divided into two equal groups, one as the experimental and the other as the control group.

Therefore, based on the result of the QPT test, 30 participants were designated and were randomly assigned to one experimental and one control group, each consisting of 15 learners. The pretest was administered to the two groups of the participants to find out the participants' ability in using the correct rhythm of English. Then, with the control group, sentences or dialogues were taught using the traditional method of instruction, as instructed in the teachers' manual. With the experimental group, however, the dynamic assessment approach was used to teach the same sentences and dialogues. More specifically, in order to carry out DA with the experimental group, there were mediations between the examiner and the examinees, in this case the teacher and the learners, such as hints, explanations, suggestions, prompts, and more importantly leading questions by the examiner. As previously mentioned, the pretest-treatment-posttest design (sandwich model of DA) was used in the study. In order to carry out the experiment, the 20 -item pretest (containing a range of declarative, imperative, exclamatory, and interrogative sentences) addressing the ability to use correct rhythm was administered in the first phase. In the second phase, mediation was provided for the experimental group. During 9 successive sessions, 30 minutes of class time was allocated to mediation and discussion of the results of their exams. Finally, the posttest which was similar in design to the pretest was administered to both groups. The collected data were analyzed using appropriate statistical procedures.

Finally, in order to investigate the experimental group students' attitudes toward the use of DA to learn to speak with a correct rhythm, a questionnaire was used consisting of 15 items developed by the researchers asking the students how much they agreed with the way they had learnt English rhythm through DA. It was administered only to the experimental group learners at the end of the treatment sessions. The mean and percentage of each item reflected the participants' level of agreement and their attitude towards the task they had done.

In the present study, both qualitative and quantitative data were collected and analyzed. The qualitative data were collected through the attitude questionnaire and quantitative data were collected and analyzed from the QPT, pretest, and posttest. In order to ensure that the pretest and posttest were reliable, inter-rater reliability method was used in this study. The researchers used Pearson correlation because two sets of interval data (i.e., test scores) were to be correlated for the pretest and two sets of scores obtained from the posttest as well were to be explored for any possible relationship between them.

\section{Results}

It was mentioned above that 30 learners were asked to take a Quick Placement Test (QPT), and were divided into two groups of experimental group (EG) and control group (CG). To make certain the two groups were indeed at the same proficiency level, their QPT scores were compared by means of an independent-samples $t$ test, the results of which are presented in Tables 1 and 2 below:

Table 1. Descriptive statistics of the QPT

\begin{tabular}{llllll}
\hline & Groups & $N$ & Mean & $S D$ & $S D$ Error Mean \\
\hline \multirow{2}{*}{ QPT } & EG & 15 & 34.63 & 3.01 & .56 \\
\cline { 2 - 6 } & CG & 15 & 35.12 & 2.43 & .47 \\
\hline
\end{tabular}


The EG learners' mean score on the placement test was 34.63 and the CG learners' was 35.12 . To determine whether the difference between these two mean scores (and thus the two groups) on the QPT was statistically significant or not, the researchers had to check the $p$ value under the Sig. (2-tailed) column in the $t$ test table below (Table 2). A $p$ value less than .05 would indicate a statistically significant difference between the two groups, and a $p$ value larger than .05 , on the other hand, shows a difference which could not reach statistical significance.

Table 2. Results of independent-samples t-test comparing the QPT scores of EG and CG

\begin{tabular}{|c|c|c|c|c|c|c|}
\hline & \multicolumn{2}{|c|}{$\begin{array}{l}\text { Levene's Test for Equality of } \\
\text { Variances }\end{array}$} & \multicolumn{4}{|c|}{$t$ test for Equality of Means } \\
\hline & $\bar{F}$ & Sig. & $t$ & $d f$ & $\begin{array}{l}\text { Sig. } \\
\text { (2-tailed) }\end{array}$ & Mean Difference \\
\hline Equal variances assumed & .24 & .32 & -.65 & 28 & .09 & -.49 \\
\hline Equal variances not assumed & & & -.71 & 27.56 & .09 & -.49 \\
\hline
\end{tabular}

Table 2 shows that there was not a statistically significant difference in QPT scores for EG $(M=34.63, S D=3.01)$ and CG $(M=35.12, S D=2.43), t(28)=-.65, p=.09$ (two-tailed). The difference between the QPT scores of the two groups was not statistically significant since the $p$ value was found to be larger than the significance level ( $p$ $=.09>.05)$. Consequently, it could be understood that the learners in the two groups were at the same level of proficiency before the experiment began.

The first research question of the study was: Does dynamic assessment have a positive effect on the Iranian EFL learners' pronunciation rhythm? To find an answer to this research question, first the pretest scores of the EG and CG learners were compared via an independent-samples $t$ test to assure that there were not any pre-existing differences between the two groups. Then another independent-sample $t$ test was employed to compare the posttest scores of the two groups. Table 3 displays the descriptive statistics for these analyses.

Table 3. Descriptive statistics for comparing pretest and posttest scores of EG and CG learners

\begin{tabular}{lllll}
\hline & $N$ & Mean & $S D$ & $S D$ Error Mean \\
\hline EG Pretest & 15 & 10.40 & 1.92 & .51 \\
CG Pretest & 15 & 10.73 & 1.86 & .48 \\
\hline EG Posttest & 15 & 15.06 & 1.57 & .40 \\
CG Posttest & 15 & 12.66 & 1.39 & .36 \\
\hline
\end{tabular}

As it can be observed in Table 3, the difference between the pretest scores of the EG $(M=10.40)$ and the CG $(M=$ $10.73)$ was very small and negligible. Nevertheless, the posttest scores of the EG $(M=15.06)$ and the CG $(M=$ 12.66) were comparatively more different. To unfold whether the differences in the pretest and posttest scores of the two groups were statistically significant or not, the following $t$ test table (Table 4) needed to be looked at:

Table 4. Results of the independent-samples t-test comparing pretest and posttest scores of EG and CG learners

\begin{tabular}{|c|c|c|c|c|c|c|c|}
\hline & & \multicolumn{6}{|c|}{$\begin{array}{l}\text { Levene's Test for Equality of } t \text { test for Equality of Means } \\
\text { Variances }\end{array}$} \\
\hline & & $\bar{F}$ & Sig. & $t$ & $d f$ & $\begin{array}{l}\text { Sig. } \\
\text { (2-tailed) }\end{array}$ & $\begin{array}{l}\text { Mean } \\
\text { Difference }\end{array}$ \\
\hline \multirow{2}{*}{ Pretest } & $\underline{\text { Equal variances assumed }}$ & .01 & .90 & -.47 & 28 & .64 & -.33 \\
\hline & Equal variances not assumed & & & -.47 & 27.88 & .64 & -.33 \\
\hline \multirow{2}{*}{ Posttest } & Equal variances assumed & .15 & .69 & -4.40 & 28 & .000 & 2.40 \\
\hline & Equal variances not assumed & & & -4.40 & 27.58 & .000 & 2.40 \\
\hline
\end{tabular}

Table 4 shows that there was not a statistically significant difference in pretest scores for EG $(M=10.40, S D=1.99)$ and CG $(M=15.06, S D=12.66), t(28)=-.47, p=.64$ (two-tailed). Thus, it could be inferred that the two groups were not significantly different at the beginning of the study with regard to their English rhythm of speech.

However, the difference between EG $(M=15.06, S D=1.57)$ and CG $(M=12.66, S D=1.39)$ posttest scores was of statistical significance due to the fact that the $p$ value under the Sig, (2-tailed) column was less than the significance 
level (i.e. $.000<.05)$. This implies that the application of DA was effective in helping EFL learners acquire the rhythm of English.

The second research question of the study was: Do the EFL learners have a positive attitude towards the use of dynamic assessment to learn rhythm? A researcher-made questionnaire was employed to find and answer to this research question. The results obtained from the questionnaire are shown in Table 5:

Table 5. Results of the attitude questionnaire

\begin{tabular}{|c|c|c|c|c|c|c|c|c|}
\hline No. & Statements & $\begin{array}{l}\text { Frequency/ } \\
\text { Percentage }\end{array}$ & $\begin{array}{l}\text { Strongly } \\
\text { agree }\end{array}$ & Agree & $\begin{array}{l}\text { No } \\
\text { opinion }\end{array}$ & Disagree & $\begin{array}{l}\text { Strongly } \\
\text { disagree }\end{array}$ & Mean \\
\hline \multirow[t]{2}{*}{1} & $\mathrm{DA}$ is preferable to & Frequency & 6 & 5 & 3 & 1 & 0 & 4.06 \\
\hline & traditional teaching. & Percentage & $40 \%$ & $33.33 \%$ & $20 \%$ & $6.66 \%$ & $0 \%$ & \\
\hline \multirow[t]{2}{*}{2} & The helps/hints & Frequency & 7 & 6 & 1 & 1 & 0 & 4.26 \\
\hline & $\begin{array}{l}\text { provided by the DA } \\
\text { were beneficial to me. }\end{array}$ & Percentage & $46.66 \%$ & $40 \%$ & $6.66 \%$ & $6.66 \%$ & $0 \%$ & \\
\hline \multirow[t]{2}{*}{3} & Peer/Teacher help was & Frequency & 4 & 6 & 2 & 2 & 1 & 3.66 \\
\hline & $\begin{array}{l}\text { very useful in the } \\
\text { English class. }\end{array}$ & Percentage & $26.66 \%$ & $40 \%$ & $13.33 \%$ & $13.33 \%$ & $6.66 \%$ & \\
\hline \multirow[t]{2}{*}{4} & I am able to understand & Frequency & 4 & 5 & 4 & 1 & 1 & 3.66 \\
\hline & $\begin{array}{l}\text { and learn pronunciation } \\
\text { better through DA. }\end{array}$ & Percentage & $26.66 \%$ & $33.33 \%$ & $26.66 \%$ & $6.66 \%$ & $6.66 \%$ & \\
\hline \multirow[t]{2}{*}{5} & I consider $\mathrm{DA}$ as an & Frequency & 3 & 7 & 2 & 3 & 0 & 3.66 \\
\hline & $\begin{array}{l}\text { effective learning } \\
\text { experience. }\end{array}$ & Percentage & $20 \%$ & $46.66 \%$ & $13.33 \%$ & $20 \%$ & $0 \%$ & \\
\hline \multirow[t]{2}{*}{6} & The hints during the & Frequency & 3 & 7 & 3 & 1 & 1 & 3.66 \\
\hline & $\begin{array}{l}\text { tests stimulated me to } \\
\text { activate my knowledge. }\end{array}$ & Percentage & $20 \%$ & $46.66 \%$ & $20 \%$ & $6.66 \%$ & $6.66 \%$ & \\
\hline \multirow[t]{2}{*}{7} & DA helped me learn & Frequency & 6 & 6 & 0 & 2 & 1 & 3.93 \\
\hline & pronunciation better. & Percentage & $40 \%$ & $40 \%$ & $0 \%$ & $13.33 \%$ & $6.66 \%$ & \\
\hline \multirow[t]{2}{*}{8} & DA can be used to learn & Frequency & 5 & 8 & 2 & 0 & 0 & 4.20 \\
\hline & $\begin{array}{l}\text { other language skills as } \\
\text { well. }\end{array}$ & Percentage & $33.33 \%$ & $53.33 \%$ & $13.33 \%$ & $0 \%$ & $0 \%$ & \\
\hline \multirow[t]{2}{*}{9} & I wish I had learned & Frequency & 5 & 7 & 3 & 0 & 0 & 4.13 \\
\hline & $\begin{array}{l}\text { English through this } \\
\text { method before. }\end{array}$ & Percentage & $33.33 \%$ & $46.66 \%$ & $20 \%$ & $0 \%$ & $0 \%$ & \\
\hline \multirow[t]{2}{*}{10} & If I were learning alone, & Frequency & 11 & 3 & 1 & 0 & 0 & 4.66 \\
\hline & $\begin{array}{l}\text { I would not have } \\
\text { improved this much. }\end{array}$ & Percentage & $73.33 \%$ & $20 \%$ & $6.66 \%$ & $0 \%$ & $0 \%$ & \\
\hline \multirow[t]{2}{*}{11} & I hope this way of & Frequency & 4 & 3 & 8 & 0 & 0 & 3.73 \\
\hline & $\begin{array}{l}\text { teaching will be also } \\
\text { used for my future } \\
\text { courses. }\end{array}$ & Percentage & $26.66 \%$ & $20 \%$ & $53.33 \%$ & $0 \%$ & $0 \%$ & \\
\hline \multirow[t]{2}{*}{12} & The interactive nature of & Frequency & 3 & 6 & 5 & 1 & 0 & 3.73 \\
\hline & DA was really helpful. & Percentage & $20 \%$ & $40 \%$ & $33.33 \%$ & $6.66 \%$ & $0 \%$ & \\
\hline \multirow[t]{2}{*}{13} & I could get answers to & Frequency & 4 & 5 & 4 & 1 & 1 & 3.66 \\
\hline & $\begin{array}{l}\text { my questions more } \\
\text { easily in this class. }\end{array}$ & Percentage & $26.66 \%$ & $33.33 \%$ & $26.66 \%$ & $6.66 \%$ & $6.66 \%$ & \\
\hline \multirow[t]{2}{*}{14} & I think I could learn & Frequency & 7 & 3 & 5 & 0 & 0 & 4.13 \\
\hline & $\begin{array}{l}\text { more pronunciation } \\
\text { skills through DA than } \\
\text { through usual classes. }\end{array}$ & Percentage & $46.66 \%$ & $20 \%$ & $33.33 \%$ & $0 \%$ & $0 \%$ & \\
\hline \multirow[t]{2}{*}{15} & Overall, I feel happy to & Frequency & 3 & 6 & 4 & 1 & 1 & 3.60 \\
\hline & have experienced DA. & Percentage & $20 \%$ & $40 \%$ & $26.66 \%$ & $6.66 \%$ & $6.66 \%$ & \\
\hline
\end{tabular}

In this questionnaire, as it could be seen, all the mean scores of the questionnaire items were above 3.00 (which is the average value of the choices when strongly agree receives 5 and strongly disagree receives 1 ). This means that the EG learners agreed with all the questionnaire items. The highest mean scores belonged to items \# 10 ( $M$ $=4.66), 2(M=4.26), 8(M=4.20)$, and $14(M=4.13)$, where the learners expresses their agreement with the propositions stating that (a) if they were learning alone (without the help they received through DA), they would 
not have improved this mush, (b) the helps/hints provided via DA were beneficial to them, (c) DA could be used to teach/learn other language skills as well, and (d) they thought they could learn more pronunciation skills through DA than through usual classes. Likewise, all the other items received the learners' agreement. To see whether the degree of this agreement was statistically significant or not, a one-sample $t$ test was conducted. This statistical tool compares the mean score of a distribution against a constant (which was 3.00 in this analysis since the choices in the Likert-scale questionnaire ranged from 1 to 5 and the average value of the choices was 3.00). Table6 shows the results of descriptive statistics performed for this purpose.

Table 6. Descriptive statistics for EG learners' attitude scores

\begin{tabular}{lllll}
\hline & $N$ & Mean & $S D$ & $S D$ Error Mean \\
\hline Attitude Questionnaire & 15 & 3.91 & .31 & .08 \\
\hline
\end{tabular}

The attitude mean score of the EG learners was found to be 3.91, which was larger than 3.00. This implies that, as stated above, the EG learners' overall attitudes towards the use of DA for learning pronunciation was positive. To find out whether this positive attitude was of statistical significance or not, the researchers had to check the Sig. (2-tailed) value in the one-sample $t$ test table (Table 7):

Table 7. One-sample t-test results for the EG learners' attitude scores

\begin{tabular}{|c|c|c|c|c|c|c|}
\hline & \multicolumn{6}{|c|}{ Test Value $=3$} \\
\hline & \multirow[b]{2}{*}{$t$} & \multirow[b]{2}{*}{$d f$} & \multirow[b]{2}{*}{ Sig. (2-tailed) } & \multirow[b]{2}{*}{ Mean Difference } & \multicolumn{2}{|c|}{$\begin{array}{l}95 \% \text { Confidence Interval of } \\
\text { the Difference }\end{array}$} \\
\hline & & & & & Lower & Upper \\
\hline Questionnaire & 11.36 & 14 & .00 & .91 & .74 & 1.08 \\
\hline
\end{tabular}

As could be seen in Table 7, there was a statistically significant difference between the EG learners' mean attitude score $(M=3.91)$ and the average value of the choices (i.e. 3.00) due to the fact that the $p$ value was smaller than the specified level of significance $(.000<.05)$. Accordingly, it could be concluded that the degree of the EG learners' positive attitude towards the application of DA in English classes, especially for the purpose of teaching pronunciation, was statistically significant (i.e. they approved of it to a considerable extent).

\section{Discussion and Conclusion}

Based on the statistical analysis of the results, the two research questions of the study were answered. To provide convincing and logical interpretations for the findings, the research hypotheses are addressed here in this section of the study one by one. The hypotheses are:

H1. Dynamic assessment has a positive effect on the Iranian EFL learners' rhythm.

H2. EFL learners have a positive attitude towards the use of dynamic assessment to learn rhythm of English.

In the following section, each research hypothesis is addressed based on the statistical analysis of the results, interpreted, and the findings are compared with previous pertinent studies.

\subsection{Addressing the First Hypothesis}

To test the first research hypothesis, the pretest mean scores of the experimental and control groups were compared at the beginning of the study on the pronunciation test to make sure they did not differ significantly before conducting the experiment. The results of the independent-samples $t$ test pointed to their homogeneity at the outset of the study. Later, at the end of the experiment, posttest mean scores of the participants were compared using another independent-samples $t$ test to unearth the impact of treatment, which was the application of DA. The analysis of the results revealed that there was a significant difference between the performance of the two groups and that the experimental group participants managed to outperform the control group members on the pronunciation posttest. Hence, the first research hypothesis was confirmed.

In dynamic assessment, the intervention of teachers/assessors causes the ZPD to be created, and this, in turn, would lead to the emergence and activation of the learners' potential. In other words, assessing a learner's learning potential means to create his or her ZPD through the intervention of the mediator. Lidz and Peña (2009) contended that DA is an approach to individual assessment based on ZPD. The internalization process leading to learner's potential proficiency involves a transformation shift from interpsychological to intrapsychological planes within 
social interaction in the ZPD, where the expert (teacher/assessor) and novice (learner) together engage in communication. The dynamic assessor instructs learners on how to perform certain tasks, provides mediated assistance on how to master them, and then measures their progress in learning to solve similar problems (Kirschenbaum, 1998). In other words, dynamic assessment goes beyond the cognitive measure of the one-shot standardized test.

The reasoning and justification presented in the preceding paragraph could provide a cogent reason why DA has been shown to be beneficial in the improvement of language skills and subskills like speaking (Ahmadi-Safa et al., 2015), reading (Mardani \& Tavakoli, 2011), and vocabulary learning (Hessamy \& Ghaderi, 2014), and pronunciation rhythm in the present study.

\subsection{Addressing the Second Hypothesis}

To test the second hypothesis, a 15 -item questionnaire was filled out by the learners in the experimental group. Analyzing the responses to the questionnaire items, it was revealed that, the learners agreed with all the statements in the questionnaire, which mainly stated that teachers' hints in a DA approach helped them with acquiring the rhythm of L2. Thus, the learners were found to have positive attitudes towards DA. In order to make sure this positive attitude was of statistical significance, the overall mean score of the items was computed $\left(M_{\text {total }}=3.91\right)$. This value was then compared against the average value of responses (i.e. 3.00) via a one-sample $t$ test. The ultimate analysis, then, showed that the experimental group learners held significantly positive attitudes towards the implementation of DA in their pronunciation classes. Therefore, the second positive hypothesis was confirmed as well.

Given that in a DA-based instruction, the learners receive individual feedback and support on their performance during a test, they are likely to take advantage of this propitious opportunity and develop a positive attitude towards such an instructional approach. This type of treatment not only makes the learners aware of their strengths and weaknesses, but also provides a scaffold for them to overcome their problems. The findings of the study as regards the second hypothesis supported some other relevant studies' results exploring the attitudes of the L2 learners being assessed through the principles of DA. Amirsheibani, Tamri, and Moghaddam (2014) and Jarrahzadeh and Tabatabaei (2015) investigated L2 learners' attitude towards using DA in the L2 classroom. The findings indicated that the participants responded favorably to DA and they generally agreed with its implementation.

Based on the result of analyzing the questionnaire, it was uncovered that DA provided the learners with the opportunity to have face to face interaction with their teacher and peers, the hints stimulated the learners to activate their knowledge, thus resulting in the improvement of their pronunciation.

\subsection{Conclusion}

Principles of DA framework offered in this study attached great importance to the process of learning pronunciation in general and rhythm in particular. Unlike other types of assessment which are mostly static and set their objectives as evaluating the level of students or providing feedback for their study, the aim of DA is promoting development. Through the interpretation of each individual learning potential, assistance is provided via the intervention of the mediator aided by other mediational tools. Since mediation is provided within the ZPD of the learners, remarkable achievement in language and critical thinking abilities are likely to occur. DA has been shown to be an effective means of determining the performance of L2 learners; hence, it can be concluded that it results in presenting a true view of the capabilities and self-regulation which definitely leads to enhancement of language skills and subskills.

As the findings indicated, DA had a positive impact on learners' pronunciation ability. Since the learning potentials of the learners are explored through DA, misinterpretations of learners' abilities are decreased to a great extent. It sheds light on current status of the learners and their hidden potential within the ZPD. And finally, from the findings of the study it can be inferred that the L2 learners themselves enjoyed being assessed dynamically, because they found it beneficial and could sense the improvement of their pronunciation.

\subsection{Implications of the Study}

Based on the results of this study on applying DA to improve pronunciation, it is highly recommended that teachers assist their students to learn in collaboration with their peers and teacher as a mediator. The findings of this study have significant implications for L2 instructors, L2 learners, and those who are involved in the area of pronunciation instruction and assessment. The results of this study demonstrated that through the implementation of DA, proper form of mediation is provided to the learners based on their ZPD. Accordingly, learners can better be engaged in the process of performing oral activities and their confidence and self-regulating ability is 
enhanced. Thus, L2 teachers are strongly recommended to apply DA principles in L2 classes enhancing pronunciation ability of their L2 learners.

As Vygotsky (1978) puts it, the only good instruction is the one that leads to development. When the learners are forced and put into a challenge for a higher cognitive level, the level of expectations for the learners themselves increases. In other words, by making the learners believe that their capabilities are more or higher than the levels they consider, this causes them to perform better and try harder for reaching the higher level. In addition, teacher must be able to recognize the levels and abilities of the learners in order to make a profit from choosing the type of assistance. Usually the significant responsibility of deciding for incorporating a scaffolding and supportive approach into assessment and instruction is with the teacher.

This framework can create a new condition for assessing pronunciation. The findings of this study might act as the baseline data for designing tests and syllabus in EFL classes. In most cases, DA does not result in ranking, scoring, and grades of the students and understanding of the learners' abilities emerged from the analysis of transcribed assessment; therefore, the outcome would be a learning environment devoid of any extraneous factor.

\section{References}

Ahmadi Safa, M., Moradi, M., \& Hamzavi, R. (2015). Iranian EFL teachers and learners perspective on potentiality of Top Notch series for intercultural competence development. Iranian Journal of Language Teaching Research, 3(2), 47-66.

Ajideh, P., \& Nourdad, N. (2012). The effect of dynamic assessment on EFL reading comprehension in different proficiency levels. Language Testing in Asia, 2(4), 1-22. https://doi.org/10.1186/2229-0443-2-4-101

Ajideh, P., Farrokhi, F., \& Nourdad, N. (2012). Dynamic assessment of EFL reading: Revealing hidden aspects at different proficiency levels. World Journal of Education, 2(4), 102-110. https://doi.org/10.5430/wje.v2n4p102

Amirsheibani, M., Tamri, M. S., \& Moghadam, S. Y. (2014). Dynamic assessment of Iranian EFL learners' writing ability. The Iranian EFL Journal, 42(3), 143.

Carney, J. J., \& Cioffi, G. (1992). The dynamic assessment of reading abilities. International Journal of Disability, Development and Education, 39(2), 107-114. https://doi.org/10.1080/0156655920390203

Deutsch, R., \& Reynolds, Y. (2000). The use of dynamic assessment by educational psychologists in the UK. Educational Psychology in Practice, 16(3), 311-331. https://doi.org/10.1080/713666083

Embretson, S. E., \& Wetzel, C. D. (1987). Component latent trait models for paragraph comprehension tests. Applied Psychological Measurement, 11(2), 175-193. https://doi.org/10.1177/014662168701100207

Foote, S., Quinney, A., \& Taylor, M. (2013). The social work assignments handbook: A practical guide for students. London: Routledge.

Hanifi, S., Nasiri, M., \& Aliasin, H. (2016). Dynamic assessment of incidental vocabularies: A case of Iranian ESP learners. Advances in Language and Literary Studies, 7(2), 163-170.

Hannon, E. E., Lévêque, Y., Nave, K. M., \& Trehub, S. E. (2016). Exaggeration of language-specific rhythms in English and French children's songs. Frontiers in Psychology, 7. https://doi.org/10.3389/fpsyg.2016.00939

Hessamy, G., \& Ghaderi, E. (2014). The role of dynamic assessment in the vocabulary learning of Iranian EFL $\begin{array}{llll}\text { learners. Procedia-Social and Behavioral } & \text { Sciences, 98, }\end{array}$ https://doi.org/10.1016/j.sbspro.2014.03.463

Jarrahzadeh, Z., \& Tabatabaei, O. (2014). Gender-based study of learners' reading ability through dynamic assessment (DA): Guthke's Lerntest approach in focus. International Journal of Foreign Language Teaching and Research, 2(7), 47-53.

Kirschenbaum, R. J. (1998). Dynamic assessment and its use with underserved gifted and talented populations. Gifted Child Quarterly, 42(3), 140-147. https://doi.org/10.1177/001698629804200302

Lantolf, J. P., \& Poehner, M. E. (2004). Dynamic assessment of L2 development: bringing the past into the future. Journal of Applied Linguistics, 1(1), 49-72. https://doi.org/10.1558/japl.1.1.49.55872

Lantolf, J. P., \& Poehner, M. E. (2011). Dynamic assessment in the classroom: Vygotskian praxis for second language development. Language Teaching Research, 15(1), 11-33. https://doi.org/10.1177/1362168810383328 
Leung, C. (2007). Dynamic assessment: Assessment for and as teaching? Language Assessment Quarterly: An International Journal, 4(1), 257-278. https://doi.org/10.1080/15434300701481127

Lidz, C. S., \& Gindis, B. (2003). Dynamic assessment of the evolving cognitive functions in children. In A. E. Kozulin, J. S. Brown, S. M. Miller, C. Heath, B. Gindis, \& V. S. Ageyev (Eds.), Vygotsky's educational theory in cultural context (pp. 99-116). Cambridge, UK, New York: Cambridge University Press. https://doi.org/10.1017/CBO9780511840975.007

Lidz, C. S., \& Peña, E. D. (2009, May). Response to intervention and dynamic assessment: Do we just appear to be speaking the same language? Seminars in Speech and Language, 30(2), 121-133. https://doi.org/10.1055/s-0029-1215719

Lin, Z. (2010). Interactive dynamic assessment with children learning EFL in kindergarten. Early Childhood Education Journal, 37(4), 279-287. https://doi.org/10.1007/s10643-009-0356-6

MacKay, D. G. (1985). A theory of the representation, organization and timing of action with implications for $\begin{array}{lllll}\text { sequencing disorders. Advances in } & \text { Psychology, 23, }\end{array}$ https://doi.org/10.1016/S0166-4115(08)61145-0

Mardani, M., \& Tavakoli, M. (2011). Beyond reading comprehension: The effect of adding a dynamic assessment component on EFL reading comprehension. Journal of Language Teaching and Research, 2(3), 688-696. https://doi.org/10.4304/j1tr.2.3.688-696

Morley, J. (1991). The pronunciation component in teaching English to speakers of other languages. TESOL Quarterly, 25(3), 481-520. https://doi.org/10.2307/3586981

Poehner, M. E. (2008). Dynamic assessment: A Vygotskian approach to understanding and promoting L2 development (Vol. 9). New York: Springer Science \& Business Media. https://doi.org/10.1007/978-0-387-75775-9

Safa, M. A., Moradi, M., \& Hamzavia, R. (2015). Iranian EFL teachers and learners perspective on potentiality of Top Notch series for intercultural competence development. Iranian Journal of Language Teaching Research, $3(2), 47-66$.

Sternberg, R. J., \& Grigorenko, E. L. (2002). Dynamic testing: The nature and measurement of learning potential. Cambridge: Cambridge University Press.

Valle, D. A. (2016, July 4-8). Playing with the suprasegmental features of speech, musicality and movement. Paper presented at $10^{\text {th }}$ European Music Therapy Conference, Vienna, Italy.

Vellenga, H. (2004). Learning pragmatics from ESL \& EFL textbooks: How likely? Tesl-Ej, 8(2), n2.

Vygotsky, L.S. (1978). Mind in society: The development of higher psychological processes. Cambridge, MA: Harvard University Press.

\section{Copyrights}

Copyright for this article is retained by the author, with first publication rights granted to the journal.

This is an open-access article distributed under the terms and conditions of the Creative Commons Attribution license (http://creativecommons.org/licenses/by/4.0/). 